\title{
CERVICAL SYMPATHETIC CHAIN SCHWANNOMA- A RARE CASE REPORT
}

\author{
Abdul Rachman Saragih"1, Devira Zahara ${ }^{2}$
}

${ }_{1}^{1}$ Faculty of Medicine, Department of Otorhinolaryngology Head and Neck Surgery, Medical Faculty, Universitas Sumatera Utara, Medan, Indonesia.

${ }^{2}$ Faculty of Medicine, Department of Otorhinolaryngology Head and Neck Surgery, Medical Faculty, Universitas Sumatera Utara, Medan, Indonesia.

HOW TO CITE THIS ARTICLE: Saragih AR, Zahara D. Cervical sympathetic chain schwannoma- a rare case report. J. Evolution Med. Dent. Sci. 2017;6(87):6084-6086, DOI: 10.14260/jemds/2017/1321

\section{PRESENTATION OF CASE}

A 49-years-old male was admitted to General Hospital of $\mathrm{H}$. Adam Malik, Medan, on 28th November 2013 with a left neck swelling from the last 10 years. The size initially was small and getting bigger as big as softball. The patient also complained of limited head movement to the left side. There was no history of neck pain, nasal blockage, nasal bleed, tinnitus, diplopia, hoarseness, dyspnoea or dysphagia. Fine needle aspiration cytology (FNAC) was done three times on October 1st, 2012 and November 21st, 2012 with the same result suggestive of Pleomorphic Adenoma and on November $30^{\text {th }}, 2013$ with a result that was suspected as Benign Cyst from the Parotid Gland.

During ENT routine examination, ears and nose were normal. The lateral wall of oropharynx and hypopharynx was towards medially, but mucosa was normal. There was no facial paralysis. There was a neck swelling at the level of sternocleidomastoid region with a size of $9.5 \times 9.5 \times 3 \mathrm{~cm}$. It was immobile, hard, smooth and no pain during palpation. The patient showed clinical finding of Horner's syndrome (Ptosis and myosis on the left eye) (Fig. 1 and 2).
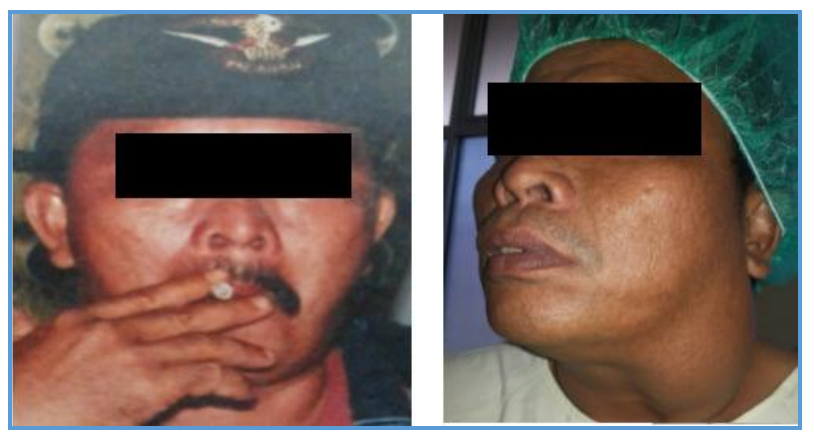

Figure 1. Left: There was no Proptosis found 6 years ago on Patient, but there was a Neck Swelling with a Small Mass. Right: Preoperatively, there was a Ptosis Sign

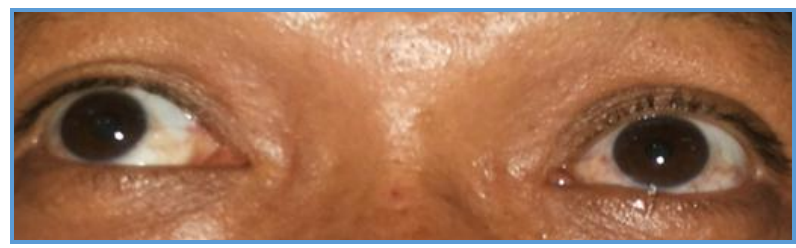

Figure 2. Horner Syndrome Sign-Myosis on the Left Eye

'Financial or Other Competing Interest': None.

Submission 05-04-2017, Peer Review 18-10-2017,

Acceptance 25-10-2017, Published 30-10-2017.

Corresponding Author:

Abdul Rachman Saragih,

JL. Kenanga 16 Medan,

Sumatera Utara, Indonesia.

E-mail: abdulrachmansaragih@yahoo.com

DOI: $10.14260 /$ jemds/2017/1321

\section{(c) (1) $(9)$}

A contrast-enhancing neck CT scan show there was a heterogenic mass with clear border and thick wall. The measured was $6.3 \times 6 \mathrm{~cm}$. The mass pushed the vascular structure (internal carotid artery/ ICA and internal jugular vein/ IJV) anteriorly and laterally, but did not separate them. The mass was situated at the level of Cervical Vertebrae $2^{\text {nd }}$. $5^{\text {th. }}$ There was no node enlargement. There was no mass in the nasopharynx or oropharynx. There was no destruction of cervical vertebrae. As conclusion, a tumour on the neck region with clear order was measured $6.3 \times 6 \mathrm{~cm}$ at the level of $\mathrm{C} 2$ - C5. The mass pushed the vascular structure to the anterior and lateral direction (Fig. 3).

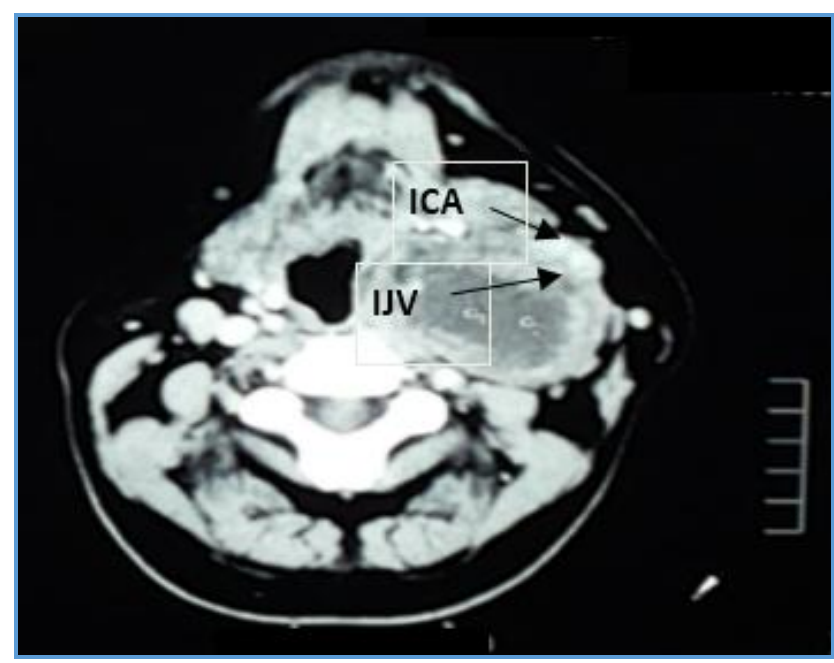

Figure 3. A Contrast-Enhancing Neck CT

ECG thorax and laboratory examination were normal.

\section{DIFFERENTIAL DIAGNOSES}

1. Cervical sympathetic chain schwannoma.

2. Benign cyst from parotid gland.

3. Lymphoma.

4. Carotid body tumour.

\section{CLINICAL DIAGNOSIS}

Cervical Sympathetic Chain Schwannoma.

\section{PATHOLOGICAL DISCUSSION}

During operation we found a yellowish rounded mass with smooth surface medial to sternocleidomastoid muscle. The mass was separated from surrounding structures with blunt dissection. The tumour was attributed to the cervical bone. The mass capsule tore off and brown-yellowish serous fluid came out from the mass. The capsule was removed completely with blunt dissection. Internal jugular vein and internal carotid artery were exposed. 
The histopathology examination described the tumour consists of dense cells (Black Arrow, Fig. 4A) surrounded by loose connective tissue (White Arrow, Fig. 4A). The dense tissue consists of the cells with oval and spindle nucleus with palisading form. The loose connective tissue with stromal myxoid was seen. The stroma composed of fibrous connective tissue with dilatation and vascular congestion. There was no sign of malignancy.

\section{CONCLUSION- Schwannoma.}

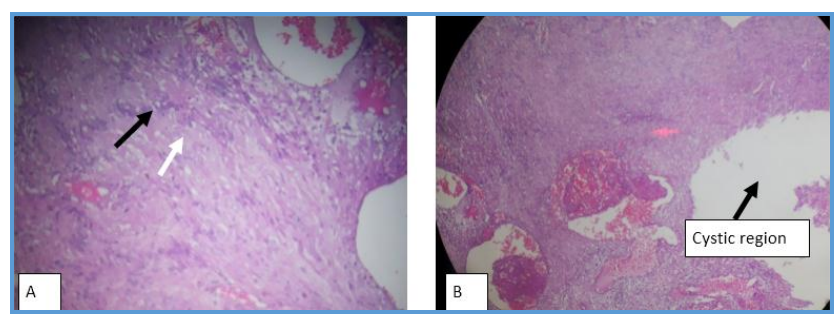

Figure 4. The Histopathology of Tumour Tissue

Schwannoma is a benign tumour that originate from the Schwann cells of the nerve sheath. Schwann cells are neural crest-derived glial cells that are responsible for providing myelin insulation to peripheral nervous system axon. ${ }^{1}$ Schwannoma may originate from any of the cranial, peripheral or autonomic nerves. Over last decades, much literature has been written on the studies on intracranial schwannoma with regards to vestibular neuroma (acoustic neuroma). Nonetheless, majority of schwannomas are nonvestibular and extracranial. ${ }^{2}$

Cervical sympathetic chain schwannoma (CSCS) are rare case. Benign tumours are derived from the superior or middle part of the cervical chain and are usually located in the parapharyngeal space retrostyloid compartment. In series of parapharyngeal space tumours, $6 \%$ were from the sympathetic chain. CSCS is generally of adult onset, $20-50$ years of age with a balanced sex ratio. ${ }^{3}$

The CSCS appear as an asymptomatic and solitary mass in the mid or upper lateral neck that grow slowly, approximately $3 \mathrm{~mm}$ per year, thus avoiding other structural compression to an advanced stage. Rarely, they arise near the vertebral foramina presenting with intraspinal and extraspinal component. The major diameter of CSCS has been between 2 and $7.5 \mathrm{~cm}$. These tumours grow at least to $2.5-3$ $\mathrm{cm}$ before they are detected. Although, schwannomas are typically benign, they may affect adjacent tissues by expansion with pressure effect. They have slow growth, low recurrence rate and are non-invasive in nature. ${ }^{3}$

Saunders (N.D) explain that histologically two types of tissue of schwannomas are seen: 1. Antoni A tissue are composed of more densely arranged cells with specific areas of palisading nuclei arranged in rows/compact groups of spindle cells with nuclei that tend to show palisading; 2 . Antoni B tissue are composed of loose reticular tissue, sometimes cystic /loose reticular tissue, sometimes cystic. A portion of the tumour usually has cells with an interlacing fascicular pattern, while in other areas there is palisading. The walls of blood vessels are often large, may show a characteristic hyalinisation. Importantly, Verocay bodieswhorled formations of palisading nuclei arranged in rows about the periphery of eosinophilic cytoplasm. ${ }^{4}$

\section{DISCUSSION OF MANAGEMENT}

The patient underwent tumour resection through a transverse left cervical skin incision on January 15th, 2014.
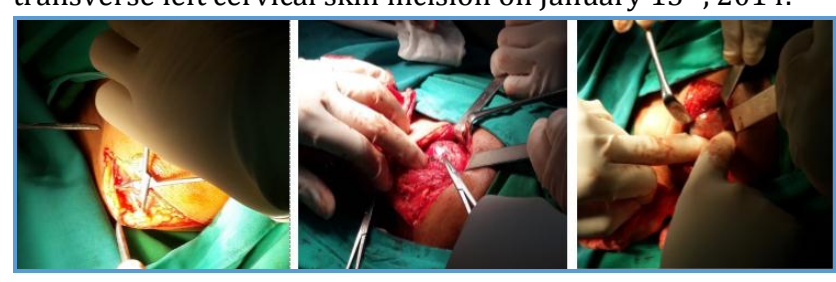

Figure 5. A Transverse Left Cervical Skin Incision (1), The Mass with Smooth Surface (2), The Mass was Excised through with Blunt Dissection (3)

Postoperatively, the patient still showed the Horner's syndrome sign such as ptosis on the left eyelid and pupil myosis. Patient comes for control to ENT clinic every 2 - 3 days. The head freely moves to the left. There was no facial paralysis found.

This patient had an asymptomatic left neck swelling for past 10 years. The neck swelling is getting bigger slowly. There was no other symptom except head limited movement to the left side recently. This symptom is probably there because of the extensive size of the mass. The swelling was situated under the left mandible superiorly and in supraclavicular region inferiorly with the size of $9.5 \mathrm{~cm} \times 9.5$ $\mathrm{cm} \times 3 \mathrm{~cm}$. The characterisation of the mass shows there was plain surface, immobile, no pressure pain and firm in consistency. The Horner's syndrome such as ptosis and myosis on the left eye was found preoperatively.

The preoperative diagnosis of schwannoma in the head and neck region is difficult. But most of the investigations like FNAC (Fine needle aspiration cytology) may help to reveal the diagnosis, but they are inadequate. FNAC is very effective in differentiating benign and malignant tumours of soft tissue. Although, FNAC is very useful in most neck masses, it has a low accuracy in the diagnosis of neural tumours. ${ }^{5}$ Liu et al reported the accuracy of FNAC was only $20 \% .^{3}$ These results are similar to the literature that FNAC is very effective in differentiating benign and malignant tumours of soft tissue, but it was different from the postoperative histopathologic test which was schwannoma.

With the lack of symptoms and physical examination findings, imaging plays the central role in diagnosing and distinguishing parapharyngeal neoplasm. On non-contrast CT, schwannoma are hypodense as compared with the muscle. Contrast administration results in some degree of enhancement, which may be homogenously solid or heterogenous. ${ }^{3}$ The heterogenicity has been attributed to cystic degeneration, xanthomatous change or areas of relative hypocellularity adjacent to densely cellular or collagenous segments. ${ }^{6}$ On MRI, schwannomas are well-circumscribed homogenous masses that exhibit high-signal intensity on T2weighted images and a relatively homogenous low-signal intensity on T1-weighted images. ${ }^{7}$ Sympathetic chain schwannoma mildly splay the carotid bifurcation, but do not separate the great vessels. On the contrary, vagal schwannoma typically separate the internal jugular vein and carotid arteries, but does not usually widen the carotid bifurcation. ${ }^{2}$

In this case, MRI was not performed. The patient underwent a contrast-enhancing neck CT scan that shows 
there was a heterogenic mass with clear border and thick wall. The measured was $6.3 \times 6 \mathrm{~cm}$. The mass pushed the vascular structure (internal carotid artery/ ICA and internal jugular vein/ IJV) anteriorly and laterally, but did not separate them. The mass was situated at the level of Cervical Vertebrae $2^{\text {nd }}-5^{\text {th }}$. There was no node enlargement. There was no mass in the nasopharynx or oropharynx. There was no destruction of cervical vertebrae. As conclusion, a tumour on the neck region with clear order measured $6.3 \times 6 \mathrm{~cm}$ at the level of $\mathrm{C} 2$ - C5. The mass pushed the vascular structure to the anterior and lateral direction.

Complete resection remains the treatment of choice. Their slow growth, low recurrence rate and non-invasive nature however often allow for an observational approach. Most parapharyngeal schwannomas were resected by transoral route with complications such as incomplete removal, serious haemorrhage, infection and cranial nerve damage. The transcervical surgical approach to the parapharyngeal space is the current preferred operation. If the schwannoma is completely removed, recurrence rates are extremely low. 4 Complete surgical removal of the mass without sacrificing nerve fibre is possible only when the capsule is easily separable from the underlying fibres; moreover, since cervical sympathetic chain damage is well tolerated. Thus, the majority of patients who undergo intervention are reported to manifest some degree of Horner's syndrome, which is the most complication after CSCS removal. ${ }^{8}$ In this case, patient underwent transcervical approach resection. The mass was separated from surrounding structures with blunt dissection. The tumour was attributed to the cervical bone. The mass capsule tore off and there was brown-yellowish serous fluid that came out from the mass. The capsule was removed completely with blunt dissection. The Horner's syndrome still exists post operation.
Patient comes for control to otorhinolaryngology outpatient clinic every 2 - 3 days. The surgical wound was dry and the head freely move to the left. Postoperatively, the patient still showed the Horner's syndrome sign such as ptosis on the left eyelid and pupil myosis.

\section{FINAL DIAGNOSIS}

Cervical Sympathetic Chain Schwannoma.

\section{REFERENCES}

[1] Yong DJ, Hailani I, Razif M. Cervical vagal schwannoma. Philippine Journal of Otolaryngology - Head and Neck Surgery 2010;25(2):23-6.

[2] Sharma DK, Sohal BS, Parmar TL, et al. Schwannomas of head and neck and review of literature. Indian J Otolaryngol Head Neck Surg 2012;64(2):177-80.

[3] Yasumatsu R, Nakashima T, Miyazaki R, et al. Diagnosis and management of extra cranial head and neck schwannomas: a review of 27 cases. International Journal of Otolaryngology 2013;2013:1-5.

[4] Wippold FJ, Lubner M, Perrin RJ, et al. Neuropathology for the neuroradiologist: antoni $\mathrm{A}$ and antoni B tissue patters. AJNR Am J Neuroradiol 2007;28(9):1633-8.

[5] Anil G, Tan TY. CT and MRI evaluation of nerve sheath tumors of the cervical vagus nerve. Am J Roentgenol 2011;197(1):195-201.

[6] Saunders WH, Wakely P. Schwannom. In: Atlas of head and neck pathology. http://ent.osu.edu/atlas-head-andneck-pathology.

[7] Saito DM, Glastonbury CM, El-Sayed IH, et al. Parapharyngeal space schwannomas: preoperative imaging determination of the nerve of origin. Arch Otolaryngol Head Neck Surg 2007;133(7):662-7.

[8] Iacconi P, Faggioni M, De Bartolomeis C, et al. Cervical sympathetic chain schwannoma: a case report. Acta Otorhinolaryngol Ital 2012;32(2):133-6. 